\title{
Informação política e atitudes sobre gastos governamentais e impostos no Brasil: evidências a partir de um experimento de opinião pública
}

\author{
Mathieu Turgeon \\ Instituto de Ciência Política \\ Universidade de Brasília \\ Lucio Rennó \\ Centro de Pesquisa e Pós-Graduação \\ sobre as Américas - CEPPAC \\ Universidade de Brasília
}

\begin{abstract}
Resumo: Não é novidade que o cidadão brasileiro, como outros vivendo em países democráticos, em média sabem pouco sobre seus governos e sobre as orientações ideológicas da maioria dos candidatos e partidos políticos. No entanto, poucos pesquisadores estudaram de maneira sistemática as conseqüências da falta de informação política para a vida democrática. Segundo alguns, a falta de informação afeta de maneira importante as atitudes políticas dos eleitores. Já para outros, a informação política não é relevante para formação de opiniões. O artigo examina essa questão no Brasil, usando pela primeira vez dados de um experimento conduzido em uma pesquisa de opinião pública realizada em 2004. Mais especificamente, examinamos como a informação sobre o governo federal brasileiro afeta as preferências políticas do cidadão em termos de gastos públicos. No experimento utilizado, alguns participantes receberam informação sobre as fontes de renda do governo federal, suas despesas e políticas públicas, enquanto outros entrevistados não receberam qualquer informação adicional. Os resultados indicam que os participantes que receberam informação política preferem menos impostos e redução nos gastos públicos daqueles que não receberam informação política. Estes resultados têm conseqüências importantes para o estudo do processo democrático, pois indicam que uma cidadania mais informada tem atitudes e preferências políticas distintas de uma menos informada.
\end{abstract}

Palavras-chave: opinião pública; informação política; atitudes políticas; gastos públicos

Abstract: We know that Brazilian citizens, just like those living in other democracies of the world, know very little about politics. We know less, however, about the consequences of political ignorance on the democratic process? Some scholars argue that the lack of political information has minimal effect of people's political attitudes and behaviors. Others, however, claim that the effects are substantial. In this paper, we examine this question using a survey-experiment conducted in Brazil in 2004. Specifically, we explore how information about the federal government affects attitudes toward government spending and taxing policies. The experiment has a control group and a treatment group where subjects in the latter were provided political information before measuring their preferred level of government spending and taxing. Results indicate that those who received political information tended to prefer less government spending and taxing, as compared to those who did not receive any information. These results carry important implications for the democratic process because they indicate that a more knowledgeable Brazilian electorate would hold different political preferences.

Keywords: public opinion; political information; political attitudes; public expenditure 


\section{Introdução}

Décadas de pesquisa, no Brasil e em outros países, corroboram que a maioria dos cidadãos sabem pouco acerca da política (BENNETT, 1989; Converse, 1964; DELLI CARPINI \& KEETER, 1996; RENNÓ, 2007). Esse é um dos poucos consensos na ciência política. O que é mais discutido, todavia, é quais são as conseqüências dessa falta de informação política sobre as atitudes e comportamentos políticos.

Segundo alguns pesquisadores, a falta de informação tem poucas consequeências porque a maioria das pessoas vota como deveria e têm atitudes "corretas" ou previsíveis, mesmo com níveis informacionais baixos. Ou seja, os eleitores comportam-se da mesma forma quando têm pouca ou muita informação política (BOWLER \& DONOVAN, 1998; LUPIA, 1994; LUPIA \& MCCUBBINS, 1998; POPKIN, 1991; SNIDERMAN, BRODY \& TETLOCK, 1991). A explicação corrente é que eleitores usam atalhos cognitivos e dicas recebidas através de redes de amigos, membros da família ou grupos para informar os seus votos e atitudes (HUCKFELDT e SPRAGUE, 1995; BAKER, AMES e RENNÓ, 2006). Por exemplo, Brady e Sniderman (1985) e Sniderman, Brody \& Tetlock (1991) sugerem que as pessoas adotam a "heurística do apresso" (likability heuristic), abraçando posições ideológicas similares às dos grupos que gostam e opostas às dos grupos que não gostam. De forma similar, Lupia (1994) acredita que os eleitores baseiam seus votos nas indicações dos grupos de interesse que apóiam causas próximas às suas. Rennó traduz o debate sobre as distintas heurísticas para o caso brasileiro, testando como as heurísticas partidárias, de apresso e de acesso, além da heurística geográfica e reputacional (SHUGART et al., 2005) contribuem para explicar o voto em deputados federais nas eleições de 2002 (RENNÓ, 2009).

Outros pesquisadores acreditam que a falta de conhecimento tem poucas conseqüências por outros motivos. Segundo Page e Shapiro (1992), por exemplo, as pessoas cometem "erros" quando fazem suas escolhas eleitorais, mas no final das contas, os erros cancelam-se quando agregados, deixando a distribuição das atitudes e preferências políticas de um grupo mais próximas às dos mais informados na sociedade. Portanto, a falta de informação individual não afeta os níveis coletivos de informação em uma sociedade. Assim sendo, segundo eles, a falta de conhecimento tem conseqüências ao nível individual mas não tem impactos ao nível agregado.

Por outro lado, muitos acreditam que a falta de informação política cria distorções importantes nas atitudes e preferências políticas de cidadãos, tanto ao nível do individual quanto ao agregado. Simulações estatísticas mostram que o conhecimento político afeta as atitudes e preferências políticas das pessoas e suas preferências eleitorais (ALTHAUS, 1998; BARTELS, 1996; DELLI CARPINI \& KEETER, 
1996; RENNÓ, 2007). Além disso, para alguns destes autores, mesmo os atalhos informacionais e dicas são desigualmente distribuídos na sociedade, levando alguns grupos a terem mais informação do que outros (DELLI CARPINI \& KEETER, 1996; RENNÓ 2007). Esses desníveis informacionais podem gerar ou aprofundar distorções no processo de representação política, com implicações sérias para a responsividade das políticas públicas às demandas de grupos específicos.

Em particular, o trabalho de Gilens (2001) demonstra, usando um experimento embutido em uma pesquisa de tipo survey, que providenciar informação específica aos entrevistados afeta suas atitudes. Da mesma forma, Fishkin e Luskin também apresentam evidências de que eleitores expostos a mais informação e a oportunidades de deliberação apresentam respostas distintas a questões de survey que eleitores que não passam por esses processos (e.g., LUSKIN e FISHKIN, 1998; LUSKIN, FISHKIN e JOWELL, 2002).

Usando um experimento similar ao de Gilens, avaliamos aqui se a obtenção de informação política afeta as atitudes políticas dos eleitores brasileiros. Os resultados indicam que afeta, e esse resultado tem implicações para a vida democrática porque indica que um eleitorado mais bem informado, pensa e vota de maneira diferente de um eleitor menos informado. Assim, encontramos evidências de que mudança nos níveis de informação política é um importante fator na formação de opiniões e atitudes políticas.

\section{Informação política e atitudes políticas}

Uma atitude política define-se como uma avaliação positiva ou negativa de certo objeto político como um partido, um programa governamental, uma política pública e assim por diante, e pode ser baseada em elementos afetivos ou cognitivos ou em ambos (SCHWART e BOHNER, 2001). Segundo alguns pesquisadores, as atitudes são avaliações pré-existentes e cristalizadas nas mentes dos cidadãos (ALLPORT 1935; SHERIF \& CANTRIL, 1947; FAZIO, 1989). Ou seja, já temos posições consolidadas sobre diversos temas, bastando então que o objeto de avaliação retorne à agenda coletiva e seja assim ativado, para que as pessoas expressem uma atitude (se for o caso) sobre o objeto considerado (WILSON \& HODGES, 1992). Em outras palavras, existe um estoque de atitudes que são ativadas com base na disponibilidade de informação e na visibilidade dos diferentes temas. Este é o modelo do "file drawer", onde as atitudes estão guardadas em "gavetas" na memória e quando necessárias, são visitadas pelo indivíduo. Este modelo, porém, tem dificuldade em explicar porque as atitudes variam tanto no tempo (CONVERSE, 1964) e são afetadas facilmente pelo contexto (SCHUMAN \& PRESSER, 1981). Ou seja, o modelo não prevê possibilidades de mudanças de atitudes no tempo. 
Uma abordagem mais recente, com enfoque em aspectos cognitivos da formação e cristalização de atitudes sugere, ao contrário, que as atitudes são avaliações mais temporárias do que fixas (STRACK \& MARTIN, 1987; TOURANGEAU, RIPS \& RASINSKI, 2000). Segundo esse modelo, as atitudes são formadas a partir de considerações (informação com conteúdo negativo ou positivo) disponíveis no momento da avaliação (ZALLER 1992; ZALLER \& FELDMAN, 1992). Nessa perspectiva, as atitudes são bem mais flexíveis e condicionadas pelo contexto do que no modelo anterior.

Em ambas as explicações, a informação política joga um papel relevante. Contudo, no modelo de "file drawer" informação política tem um papel menor, que apenas ativa uma atitude latente. Já para os que vêem as atitudes como mais etéreas, o papel da informação sobre as atitudes políticas é central, pois as considerações que um indivíduo utiliza para formar uma atitude variam no tempo e no espaço, dependendo do contexto em que estão inseridos e das informações a que tem acesso. Informação política deixa de ser apenas um gatilho de uma atitude já formada, mas molda a própria atitude que se evidenciará em uma preferência declarada ou comportamento político específico. Em nosso estudo, compartilhamos mais claramente essa última perspectiva. Nosso modelo pressupõe que 0 fornecimento de informação sobre um certo objeto político poderia afetar as considerações disponíveis para a formação de uma atitude sobre deste objeto.

É justamente isto que Gilens (2001) observa em seu estudo sobre os gastos públicos. Os participantes de seu estudo experimental receberam informação específica sobre um assunto político. Comparando dois grupos de indivíduos, o primeiro informado sobre a queda da taxa de criminalidade nos Estados Unidos e o sgundo grupo, sem acesso a essa informação, o autor encontrou menor apoio aos gastos públicos para a construção presídios entre os indivíduos do primeiro grupo. Comparando igualmente um primeiro grupo informado sobre os gastos marginais do governo americano na ajuda de países pobres $(0.1 \%$ do total de gastos governamentais) e um segundo grupo sem essa informação, o apoio aos gastos do governo foi mais aceito entre os indivíduos do grupo informado.

O trabalho de Gilens é instrutivo porque demonstra de maneira sistemática, usando um desenho de pesquisa experimental, que as pessoas estão dispostas a rever suas atitudes quando recebem informação relevante sobre certo objeto de avaliação. Nos casos citados acima, os participantes não pensaram ser necessário aumentar os gastos na construção de novos presídios se, na verdade, o crime havia diminuído nos últimos anos. Similarmente, quando receberam informações sobre a participação tímida do governo federal americano na ajuda aos países mais pobres, os participantes mostraram-se mais receptivos a aumentá-la.

Assim, a formação ou a mudança de atitude acerca de um certo objeto político ocorre quando o conjunto de considerações relacionadas a tal objeto sofre 
alguma alteração. No caso de Gilens, a informação fornecida aos participantes do experimento, alterou as considerações accessíveis no momento da avaliação. As implicações deste resultado são importantes para nosso trabalho porque sabemos que o conjunto de considerações que uma pessoa típica possui sobre a maioria dos fenômenos políticos é pequena (dado o fato que o conhecimento político da maioria dos eleitores é baixa). Existe então uma forte probabilidade de que qualquer informação adicional afete de maneira substancial as considerações e avaliações dos eleitores, e, conseqüentemente, deve produzir um efeito importante nas atitudes individuais.

\section{Metodologia}

Um experimento embutido em uma pesquisa de opinião pública, desenhado especificamente para testar a hipótese de que informação política afeta as atitudes e posicionamentos individuais, foi conduzido no Brasil em novembro de 2004 pela empresa Market Analysis Brazil. O objetivo da pesquisa, uma das primeiras a usar grupos de controle e experimentais no Brasil, era examinar o efeito da informação política sobre as atitudes acerca das despesas dos governos brasileiros ${ }^{1}$.

O experimento inclui cinco grupos de tratamento, ou experimentais, e um grupo de controle ${ }^{2}$. Porém, aqui compararamos apenas um dos grupos de tratamento e o de controle, pois este recebeu mais informação política pertinente ao tema aqui explorado. Os participantes do grupo de controle tiveram primeiro que

\footnotetext{
${ }^{1} \mathrm{O}$ uso de experimentos na ciência política, principalmente em estudos de comportamento político e eleitoral, tem crescido exponencialmente nos Estados Unidos desde os estudos pioneiros realizados na Stony Brook University nos anos 80 (DRUCKMAN ET AL, 2006). No Brasil e América Latina, estudos que aplicam o método experimental são ainda raros. Há alguns estudos que analisam a recepção de mensagens políticas por eleitores, expondo-os à diferentes tipos de propaganda eleitoral e posteriormente medindo o impacto através de questionários ou grupos focais (PORTO, 2007; DESPOSATO, 2009). Temos informações que há outros estudos experimentais em andamento atualmente no Brasil, mas seus resultados ainda não foram divulgados.

2 Reconhecemos as limitações das pesquisas de opinião pública conduzidas por telefone no Brasil dada a desigual cobertura de telefones fixos no país, embora esse fator tenha sido atenuado nos últimos anos. Não obstante, esse aspecto da cobertura telefônica afeta a representatividade da amostra em relação à população brasileira, privilegiando, por exemplo, setores urbanos e mais ricos. Porém, não acreditamos que afete de maneira sistemática os resultados experimentais apresentados aqui. Na verdade, a grande maioria das pesquisas experimentais, no Brasil ou no resto do mundo, usa amostras de conveniência, com grupos específicos como alunos da graduação. A tradição dos estudos experimentais nos Estados Unidos vai muito nessa linha. Neste sentido, nossa amostra revela-se nitidamente superior a maioria das amostras usadas em pesquisas experimentais, pois não se baseia apenas na acessibilidade aos entrevistados e inclui eleitores que moram em diversas cidades do país e respeitando cotas que assemelham-se à distribuição da população brasileira. Os participantes foram recrutados em dez grandes cidades do Brasil e as entrevistas foram conduzidas por telefone. A amostra, então, não é representativa da população brasileira mas respeita as cotas de gênero, idade e faixas econômicas segundo a Associação Nacional de Empresas de Pesquisa (ANEP). Os números de telefones foram escolhidos aleatoriamente por um computador usando os DDD das cidades incluídas no estudo e os participantes foram novamente selecionados aleatoriamente dentro dos domicílios. No total foram 1051 entrevistas concluídas, com a taxa de resposta de $29,1 \%$.
} 
responder à pergunta sobre o seu nível preferido de gastos do governo federal, seguido por cinco perguntas de conhecimento acerca das despesas e fontes de renda do governo federal e políticas públicas. Os participantes do grupo de tratamento, por sua vez, responderam primeiro às cinco perguntas de conhecimento e depois à pergunta sobre o nível preferido de gastos dos governos. Ou seja, a formulação das perguntas era idêntica, mas seu ordenamento no questionário, distinto.

Além disso, os participantes do grupo de tratamento foram informados sobre as respostas corretas às perguntas de conhecimento político quando não a acertavam. Quando o participante acertava a resposta, o entrevistador 0 congratulava e repetia a resposta. Por outro lado, quando o participante oferecia uma resposta errada, o entrevistador comunicava, de maneira respeitosa, que a resposta correta era outra e a anunciava para o entrevistado. Os participantes do grupo de tratamento, então, tiveram a oportunidade de receber informação sobre o assunto tratado antes de expressarem suas preferências sobre gastos públicos e impostos. O grupo de controle não teve acesso a qualquer informação política antes de declararem suas preferências sobre esse mesmo tema. O grupo de controle contou com 181 participantes e o grupo de tratamento com 176.

A pergunta a respeito do volume preferido de gastos dos governos brasileiros é a seguinte:

"Como você sabe, as pessoas pensam de diferentes maneiras sobre as funções dos governos. Algumas pessoas pensam que os governos federal, estadual e municipal, deveriam reduzir os impostos mesmo se isso significasse fornecer menos serviços. Outras pessoas acham que o importante é que os governos forneçam mais serviços mesmo se isso significasse aumentar os impostos. Já outras pessoas acham que os governos não deveriam fazer mudanças nem nos impostos nem nos serviços. Na sua opinião, os governos deveriam aumentar, diminuir ou manter os impostos e os serviços como estão?"

Para os entrevistados que escolheram aumentar ou diminuir os impostos e os serviços, a seguinte pergunta também foi feita:

Você acha que os impostos e os serviços devem aumentar/diminuir pouco, médio ou muito?

Com esta pergunta, construímos uma escala de sete pontos onde 1 indica que o participante prefere reduzir muito os gastos públicos e impostos, 2 indica que 0 governo deve reduzir os impostos medianamente, 3 aponta para uma preferência declarada por pouca redução, 4 indica que o entrevistado deseja mantê-los como estão, 5 aponta para uma preferência por aumentar um pouco os gastos e 
impostos, 6 para um aumento médio e 7 para muito aumento de gastos e impostos.

As questões de conhecimento avaliaram a capacidade dos participantes de identificar as áreas nas quais o governo federal gasta mais e menos, a principal fonte de renda do governo federal, a evolução da dívida externa e as conseqüências da reforma da previdência nos gastos da área ${ }^{3}$.

O tratamento em nosso experimento tem por objetivo informar os participantes, de forma a diferenciar as atitudes "normais", sem informação adicional, das atitudes mais informadas. É importante notar que o tratamento aqui proposto é diferente daquele empregado por Gilens, onde só uma informação foi dada aos participantes. No nosso experimento, os participantes recebem cinco informações importantes acerca dos governos. As informações também são balanceadas, no sentido que algumas podem levar os participantes a preferira redução dos gastos enquanto outras poderão ter o efeito oposto, estimulando os entrevistados a querer aumentar os gastos públicos. Por isso, consideramos que nosso desenho experimental se aproxima do Deliberative Poll de Fishkin e Luskin, onde os participantes recebem informação balanceada acerca de vários assuntos políticos. A diferença, porém, esta em que em nosso desenho de pesquisa os participantes não tem a oportunidade de deliberar com os demais participantes, como ocorre com os Deliberative Polls.

\section{Resultados}

Alguns trabalhos anteriores já mostraram que as atitudes políticas e os resultados eleitorais poderiam ser diferentes caso a cidadania fosse mais informada politicamente. Althaus (1998), por exemplo, mostrou que um eleitorado americano mais informado preferiria uma política externa menos agressiva e políticas sociais mais progressistas. Bartels (1996), examinando as eleições presidenciais americanas de 1972 a 1992, mostrou que a falta de conhecimento político das massas beneficia principalmente os candidatos Democratas.

Quais são, então, os efeitos da informação sobre as atitudes sobre os gastos governamentais e impostos no Brasil? O gráfico 1 apresenta a distribuição das atitudes expressas pelos participantes dos dois grupos (controle e experimental). Como podemos ver, os participantes que receberam informação geralmente preferem que os gastos e impostos sejam reduzidos. Mais especificamente, enquanto $45,4 \%$ dos participantes do grupo de controle expressaram preferência pela redução dos gastos e impostos dos governos, mais de 55,3\% dos participantes que receberam informação, o grupo de tratamento, preferiram reduzir os gastos $\mathrm{e}$ impostos. A média, baseada na escala de 1 a 7 apresentada acima, é de 3,31 (erro

\footnotetext{
${ }^{3}$ Os enunciados e alternativas de resposta das perguntas estão no anexo do texto.
} 
padrão de 0,12 ) para o grupo de controle e de 3,08 (erro padrão de 0,12 ) para 0 grupo de tratamento. Em um teste $t$ de diferença de médias, 0 valor $t$ é estaticamente significativo ao nível 0,10 (teste unilateral). Este resultado apenas sugere que um eleitorado brasileiro mais informado acerca do governo federal tenderia a preferir uma ligeira redução do papel do Estado.

\section{Gráfico 1}

Preferências expressas pelos participantes dos grupos experimental e de controle acerca de gastos públicos e impostos no Brasil, 2004.

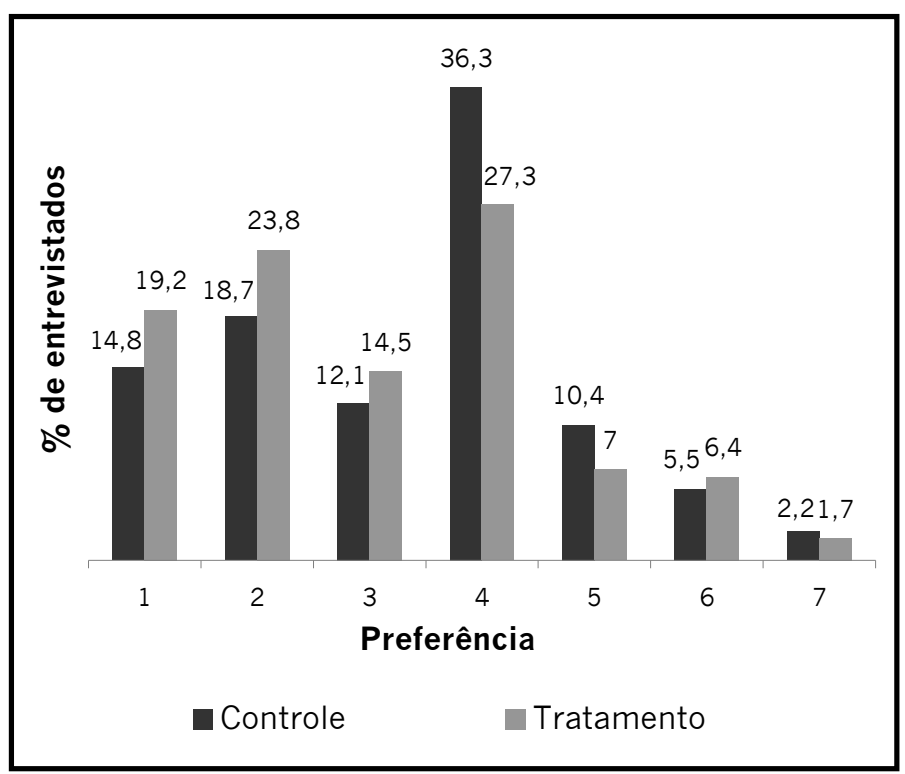

Existem, obviamente, outros fatores que podem afetar as preferências e atitudes políticas dos eleitores, o que nos levou a realizar também uma análise multivariada controlada por esses outros fatores. Assim, além de incluir uma variável dicotômica indicando pertencimento ao grupo experimental, inserimos variáveis socioeconômicas importantes como escolaridade, informação política prévia e classe econômica.

O modelo sugerido inclui primeiro uma medida dos bens dos entrevistados como proxy de seu estrato social. A expectativa é que os participantes com maior número de posses prefiram menos gastos e impostos, porque esses cidadãos geralmente pagam mais impostos e também se beneficiam menos dos serviços 
governamentais, comparados principalmente aos indivíduos com menos posses. Esse é o caso, seguramente, da situação da saúde e educação pública (à exceção da educação universitária), que não é utilizada pela classe média e alta no Brasil. 0 segundo fator explicativo que exploramos é o nível de confiança nos governos; a hipótese aqui é que os participantes menos confiantes nos governos devam preferir um papel reduzido dos governos e, consequentemente, preferir a redução nos gastos e impostos.

Controlamos também por dois fatores sempre destacados pela literatura especializada para explicar a heterogeneidade dos comportamentos e preferências dos indivíduos: escolaridade e conhecimento político dos participantes ${ }^{4}$. A escolaridade é medida numa escala de 10 pontos onde 1 indica os participantes analfabetos ou com primário incompleto e 10 aqueles que possuem pós-graduação. O conhecimento político, por sua parte, é medido numa escala de 0 a 5 , indicando - número de respostas corretas às perguntas de conhecimento político apresentadas acima ${ }^{5}$. Diferentemente das variáveis que medem estrato social e confiança no governo, não temos expectativas quanto à direção dos efeitos dessas duas variáveis, já que não há argumento teórica sobre como o conhecimento político e a escolaridade afetam as atitudes. Ou seja, não há por que supor que eleitores com maior nível educacional ou mais informação política prefiram redução nos gastos públicos e impostos. Esperamos, apenas, que as variáveis sejam estatisticamente significativas.

Finalmente, e essa é a principal variável de nosso estudo, o modelo conta com uma variável dicotômica que indica se o participante foi recrutado para participar do grupo de controle ou do grupo de tratamento. O objetivo dessa variável é verificar se há um efeito estaticamente significativo de ter recebido informações adicionais sobre o governo nas atitudes acerca de impostos e gastos governamentais. Aqui também não temos expectativa teórica quanto à direção do efeito da variável. Porém, dados os resultados do teste de diferença de médias apresentados acima, queremos verificar se os eleitores mais informados estão mesmo menos propensos a pagar mais impostos e a defender mais gastos públicos.

A Tabela 1 apresenta os resultados da regressão linear de mínimos quadrados comuns ${ }^{6}$. Como o $\mathrm{R}^{2}$ indica, o modelo tem um poder explicativo limitado

\footnotetext{
${ }^{4}$ Vale ressaltar que a correlação entre essas duas variáveis é positiva, como se espera, mas relativamente baixa, o que não compromete a inclusão das duas no modelo $(r=0,31)$.

${ }^{5}$ Os detalhes sobre a operacionalização dessas duas variáveis estão no anexo.

${ }^{6}$ A variável dependente é ordinal, como indicado no texto, e tem valores que vão de 1 a 7 . Este tipo de variável é normalmente estimado usando um logit ou probit ordinal. Porém, quando a variável tem mais de 5 pontos numa escala é prática comum simplesmente usar os mínimos quadros lineares como no nosso caso. De toda forma, reproduzimos as análises com os modelos logit e probit ordinal. Os resultados são os mesmos que aqueles apresentados aqui.
} 
$\left(R^{2}=0,02\right)$. Isso se deve ao fato de que variáveis nominais e ordinais de opinião incorporam uma maior imprecisão do que as variáveis numéricas, contínuas, de dados agregados, como indicadores econômicos, afetando a precisão de estimativas sobre elas. Assim, o $\mathrm{R}^{2}$ nesse tipo de estudo não costuma ser grande. Por outro lado, a baixa capacidade explicativa do modelo também se deve às limitações dos dados com que trabalhamos. Há diversas outras variáveis que poderiam explicar as preferências por gastos públicos e impostos, como as predisposições ideológicas do participante e suas preferências partidárias, mas infelizmente, não dispomos dessas variáveis. Além disso, a quantidade de bens dos participantes, proxy para seu estrato socioeconômico, e a confiança que eles têm nos governos não têm efeitos estatisticamente diferentes de zero, apesar de se mostrarem a direção esperada. A escolaridade também não explica a variação nas preferências dos participantes. Este resultado é similar ao de Almeida (2007) que não encontra um efeito claro dos níveis de escolaridade nas preferências sobre maior ou menor intervenção estatal. Similarmente, o conhecimento político prévio do entrevistado não afeta as atitudes políticas. Por um lado, a ausência de efeito dessas variáveis indica que a alocação aleatória dos entrevistados para os grupos de controle e de tratamento surtiu efeito, mostrando que esses dois grupos são bastante equivalentes nas variáveis que controlamos. Essa é a essência da lógica experimental: controla-se por várias características dos participantes ao alocar-los aleatoriamente para um grupo que recebe um estímulo controlado e outro não.

Apesar do número de variáveis utilizadas, o importante em nossa análise é que mesmo controlando por algumas características dos entrevistados que poderiam influenciar suas visões sobre gastos públicos e impostos, ainda assim encontramos efeito da nossa principal variável independente; exposição a mais informação política. Portanto, a ausência de impacto não significa que as variáveis independentes não possam ter efeito sobre preferências políticas em amostras maiores e mais representativas da população. Nossos resultados apenas indicam que, quando controlamos por esses fatores, acréscimos na quantidade de informação política fazem diferença nas atitudes dos eleitores.

Ou seja, a variável dicotômica que diferencia os participantes do grupo de tratamento do grupo de controle mostra um efeito significativo, comprovando que a obtenção de mais informação afeta a formação de atitudes. O coeficiente, por ser negativo, indica que os participantes do grupo de tratamento, que receberam informação política, preferem menos gastos e impostos federais que os participantes do grupo de controle. Este resultado confirma o resultado apresentado e indica claramente que a aquisição de informação política tem efeito sobre as atitudes políticas. 
Tabela 1

Coeficientes de regressão linear para atitudes acerca de gastos públicos e impostos no Brasil, 2004.

\begin{tabular}{|l|c|}
\hline Variáveis & Gastos e impostos \\
\hline Quantidade de Bens (estrato sócio-econômico) & $-0,01$ \\
& $(.02)$ \\
\hline Confiança no Governo & 0,12 \\
& $(0,09)$ \\
\hline Grupo Experimental & $-0,32^{*}$ \\
& $(0,19)$ \\
\hline Escolaridade & 0,01 \\
& $(0,05)$ \\
\hline Conhecimento político & $-0,11$ \\
& $(0,08)$ \\
\hline Constante & 3,31 \\
& $(0,36)$ \\
\hline Número de observações & 290 \\
\hline R $^{2}$ & 0,02 \\
\hline
\end{tabular}

Coeficientes estimados com o estimador de mínimos quadrados comuns. Erros padrão em parênteses. $* \mathrm{p}<.05$ (teste unilateral)

\section{Considerações finais}

Sabemos hoje que a maioria dos cidadãos brasileiros, como em outras partes do mundo, sabem pouco acerca da política. Porém, nós, cientistas sociais sabemos ainda menos sobre as conseqüências da falta de informação política para a vida democrática. Este artigo contribui para esse debate, avaliando a importância da informação política através de um experimento inserido em uma pesquisa de opinião pública. Os resultados da pesquisa mostram que a informação política teve um efeito significativo sobre as atitudes acerca dos governos brasileiros. Para avaliar o efeito da informação, comparamos as atitudes "normais" dos participantes do grupo de controle com as atitudes mais informadas dos participantes do grupo de tratamento, controlando por diversos outros fatores explicativos para a variação em atitudes políticas. Os resultados indicam que um eleitorado mais informado prefere reduzir os gastos e impostos dos governos, ou seja, reduzir o papel do estado.

Contudo, a maior contribuição deste artigo é indicar que a informação política afeta as preferências individuais dos eleitores brasileiros. Encontramos que 
quando eleitores recebem alguma informação no momento em que estão respondendo ao questionário, suas preferências e atitudes mudam. Isso é um forte indício do caráter contextual da formação de atitudes, de sua instabilidade no tempo e do grande papel que a informação política tem na definição das atitudes e preferências de indivíduos. Portanto, nossos achados questionam a literatura que minimiza a influência da informação política em decisões, escolhas e atitudes políticas.

Para além dessa questão substantiva, também podemos inferir que a opinião pública, mensurada através de surveys, é bastante sensível ao grau de informação dos eleitores e ordenamento das questões nos questionários. Nesse sentido, as respostas dos entrevistados podem deixar de ser representativas da população para as quais se busca fazer inferências, dependendo do desenho do questionário.

As implicações mais gerais desses achados não são desprezíveis, tanto para os estudos sobre informação política, quanto para a utilização de pesquisas de opinião para fins governamentais ou eleitorais. Eleitorados mais informados comportam-se de forma distinta de eleitorados menos informados e isso é expresso em suas respostas à pesquisas de opinião. Como tais pesquisas têm se tornado mecanismo rotineiro de divulgação das preferências dos cidadãos, bem como influenciado decisões sobre políticas públicas e campanhas eleitorais, é fundamental que sejam analisadas quanto à influência exercida pelo desenho do questionário e o momento histórico em que são realizadas. Dessa forma, quanto mais transparência na divulgação das pesquisas, mais compreensíveis e confiáveis são seus resultados.

Por outro lado, fica claro que o impacto da informação política em atitudes políticas declaradas não é trivial e que uma cidadania mais bem informada sobre política pensa diferentemente de uma menos informada.

\section{Referências Bibliográficas}

ALMEIDA, A. A Cabeça do Brasileiro. São Paulo: Record, 2007.

ALLPORT, G. W. Attitudes. In: MURCHISON, C. (ed.). Handbook of Social Psychology. Worcester: Clark University Press, 798-844, 1935.

ALTHAUS, S. L. "Information Effects in Collective Preferences." American Political Science Review, 92: 545-558, 1998. 
AMES, B; BAKER A. e RENNÓ, L. The Quality of Elections in Brazil: Policy, Performance, Pageantry, or Pork? In: Kingstone, Peter and Power, Timothy (eds.). Democratic Brazil Revisited. Pittsburgh: University of Pittsburgh Press, 2008.

BAKER, A; AMES, B. e RENNÓ, L. "Social Context and Campaign Volatility in New Democracies: Networks and Neighborhoods in Brazil's 2002 Elections." American Journal of Political Science. 50:2, p. 2006.

BARTELS, L. M. "Uninformed Voters: Information Effects in Presidential Elections." American Journal of Political Science, 40: 194-230, 1996.

BENNETT, S. E. "Trends in American's Political Information." American Politics Quarterly, 17: 422-35, 1989.

BOWLER, S and DONOVAN, T. Demanding Choices: Opinion, Voting, and Direct Democracy. Ann Arbour: University of Michigan Press, 1998.

BRADY, H. E., and SNIDERMAN, P. M. "Attitude Attribution: A Group Basis for Political Reasoning." American Political Science Review, 79: 1071.78, 1985.

CONVERSE, P. E. The Nature of Belief Systems in Mass Publics. In: APTER, D. E. (ed.). Ideology and Discontent. New York: Free Press, 1964.

DELLI CARPINI, M. X., and KEETER, S. What Americans Know About Politics and Why It Matters. New Haven: Yale University Press,1996.

DESPOSATO, S. Estratégia Eleitoral com Representação Proporcional de Lista Aberta e Distritos Uninominais: Subeleitorados e Comunicação Política. In: INÁCIO, M. e RENNÓ, L. (eds.). Legislativo Brasileiro em Perspectiva Comparada. Belo Horizonte: Editora da UFMG, 2009.

DRUCKMAN, J. N., GREEN, D. P; KUKLINSKI J. H; e LUPIA, A. "The Growth and Development of Experimental Research in the American Political Science Review." American Political Science Review, 100: 627-636, 2006.

FAZIO, R. H. On the Functionality of Attitudes: The Role of Attitude Accessibility, In: PRATKANIS, A.R; BRECKLER, S.J. and GREENWALD, A.G. (eds.). Attitude Structure and Function. Hillsdale: Erlbaum, 153-179, 1989.

GILENS, M. "Political Ignorance and Collective Policy Preferences." American Political Science Review, 95: 379-396, 2001.

HUCKFELDT, R. and SPRAGUE, J. Citizens, Politics, and Social Communication. Cambridge: Cambridge University Press, 1995. 
LUPIA, A. "Shortcut versus Encyclopedias: Information and Voting Behavior in California Insurance Reform Elections." American Political Science Review, 88: 63. 76, 1994.

LUSKIN, R. C. and FISHKIN. J. S. "Deliberative Polling, Public Opinion, and Democracy: The Case of the National Issues Convention." Paper presented at the American Association for Public Opinion Research Annual Meeting in St.-Louis, MO, 1998.

LUSKIN, R. C; FISHKIN, J. S. and JOWELL, R. "Considered Opinions: Deliberative Polling in the U.K.", British Journal of Political Science, 32: 455.487, 2002.

PAGE, B. I, and SHAPIRO, R. Y. The Rational Public: Fifty Years of Trends in Americans' Policy Preferences. Chicago: University of Chicago Press, 1992.

POPKIN, S. L. The Reasoning Voter: Communication and Persuasion in Presidential Campaigns. Chicago: University of Chicago Press, 1991.

PORTO, M. P. Televisão e política no Brasil: A Rede Globo e as interpretacões da audiência. Rio de Janeiro: E-papers, 2007.

RENNÓ, L. "Desigualdade e informação política: as eleições brasileiras de 2002." Dados (Rio de Janeiro), 50: 721-55, 2007.

. "Os militantes são mais informados? Desigualdade e informação política nas eleições de 2002." Opinião Pública 12: 329.47, 2006.

. Atalhos Cognitivos em Contextos Eleitorais Complexos: As eleições de 2002 do Legislativo Brasileiro. In: INÁCIO, M. e RENNÓ, L. (eds.). Legislativo Brasileiro em Perspectiva Comparada. Belo Horizonte, Editora da UFMG, 2009.

SCHUMAN, H. e STANLEY P. Questions and Answers in Attitude Surveys: Experiments on Question Form, Wording and Content. New York: Academic Press, 1981.

SCHWART, N. e BOHNER, G. The Construction of Attitudes. In: TESSER, A. and SCHWARTZ, N. (eds.) Blackwell Handbook of Social Psychology: Intraindividual Processes. Malden: Blackwell Publishing, 2001.

SHERIF, M. e HADLEY, C. The Psychology of Ego-Involvements: Social Attitudes and Identification. New York: Wiley, 1947.

SHUGART, M.; MELODY, V. and SUOMINEN, K. "Looking for Locals: Voter Information Demands and Personal Vote-Earning Attributes of Legislators under Proportional Representation." American Journal of Political Science, 49:2, 2005. 
SNIDERMAN, P. M; BRODY, R. A. and TETLOCK P. E. Reasoning and Choice:

Explorations in Political Psychology. New York, NY: Cambridge University Press, 1991.

STRACK, F. and MARTIN, L. "Thinking, Judging, and Communicating: A Process

Account of Context Effects in Attitude Surveys." In: HIPPLER, H; SCHWARTZ, N. and SUDMAN, S. (eds.). Social Information Processing and Survey Methodology. New York: Springler Verlag, 1987.

TOURANGEAU, R e RIPS, L. J. and RASINSKI, K. The Psychology of Survey Response, Cambridge: Cambridge University Press, 2000.

WILSON, T. and HODGES, S. Attitudes as Temporary Constructs. In: TESSER, A. and MARTIN, L. (eds.), The Construction of Social Judgment. Hillsdale, NJ: Erlbaum, 1992.

ZALLER, J. The Nature and Origins of Mass Opinion. New York, NY: Cambridge University Press, 1992.

ZALLER, J; and FELDMAN, S. "A Simple Theory of the Survey Response: Answering Questions versus Revealing Preferences." American Journal of Political Science, 36: 579-616, 1992.

\section{Anexo}

\section{A. Perguntas de conhecimento político:}

Agora, vou the fazer algumas perguntas sobre os governos de modo geral. Queremos saber quanta informação chega até o público através da TV, os jornais, e outras fontes. Se você não souber a resposta, não faz mal. É só me dizer e passaremos para a pergunta seguinte.

1. Pelo que você sabe ou escutou falar, em quais das seguintes áreas os governos no Brasil gastaram MAIS em 2003?
A. Defesa nacional
B. Previdência social
C. Cultura
D. Saúde

2. Pelo que você sabe ou escutou falar, em quais das seguintes áreas os governos no Brasil gastaram MENOS em 2003? 

E. Defesa nacional
F. Previdência social
G. Cultura
H. Saúde

3. Pelo que você sabe ou escutou falar, qual foi a principal fonte de verbas do governo federal em 2003?

I. Imposto de renda pessoa física

J. Imposto pagos pelas empresas

K. Impostos sobre bebidas alcoólicas

L. Impostos sobre importações

4. Pelo que você sabe ou escutou falar, a dívida pública do Brasil (federal, estadual e municipal) aumentou, diminuiu ou ficou igual desde o início do ano?
A. Aumentou
B. Diminuiu
C. Ficou igual

5. Pelo que você sabe ou escutou falar, a recente reforma da previdência aprovada pelo governo Lula vai fazer aumentar, diminuir ou deixar igual o tamanho do gasto com previdência social nos próximos anos?
A. diminuir
B. deixar igual
C. aumentar

\section{B. Construção das variáveis independentes}

1. Bens: esta variável mede as posses dos entrevistados como proxy de seu estrato social. A variável tem valores de 4 a 34 , onde valores maiores representam mais posses. A título ilustrativo, a Associação Nacional de Empresas de Pesquisa usa esses valores para classificar as famílias segundo sete classes econômicas: A1 (30. 34, $1 \%$ da população), A2 (25-29, 5\% da população), B1 (21-24, 9\% da população), B2 (17-20, 14\% da população), C (11-16, 36\% da população), D (6.10, 31\% da população), e E (0-5, 4\% da população).

2. Confiança nos governos: esta variável mede o nível de confiança nos governos dos entrevistados. A variável é medida numa escala de 4 pontos onde 1 identifica que os participantes não têm confiança nos governos, 2 indica pouca confiança, 3 alguma confiança e o valor 4 indica muita confiança. 
3. Escolaridade: esta variável classifica os participantes da seguinte forma numa escala de 10 pontos: 1 indica os analfabetos ou aqueles com primário incompleto, 2 primário completo, 3 ginásio incompleto, 4 ginásio completo, 5 segundo grau incompleto, 6 segundo grau completo ou técnico incompleto, 7 técnico completo, 8 superior incompleto, 9 superior completo e 10 pós-graduação.

4. Conhecimento político: esta variável mede o conhecimento político dos participantes segundo a sua habilidade de responder corretamente as cinco perguntas de conhecimento político apresentadas acima. Cada resposta correta vale 1 ponto e assim o conhecimento político vai de 0 (o participante errou todas as perguntas) a 5 (o participante respondeu corretamente todas as perguntas).

Mathieu Turgeon - turgeon@unb.br

Lucio Rennó - Iuciorenno@unb.br

Recebido para publicação em dezembro de 2009. Aprovado para publicação em abril de 2010. 